\title{
Hommage à Naima Louali (1961-2005)
}

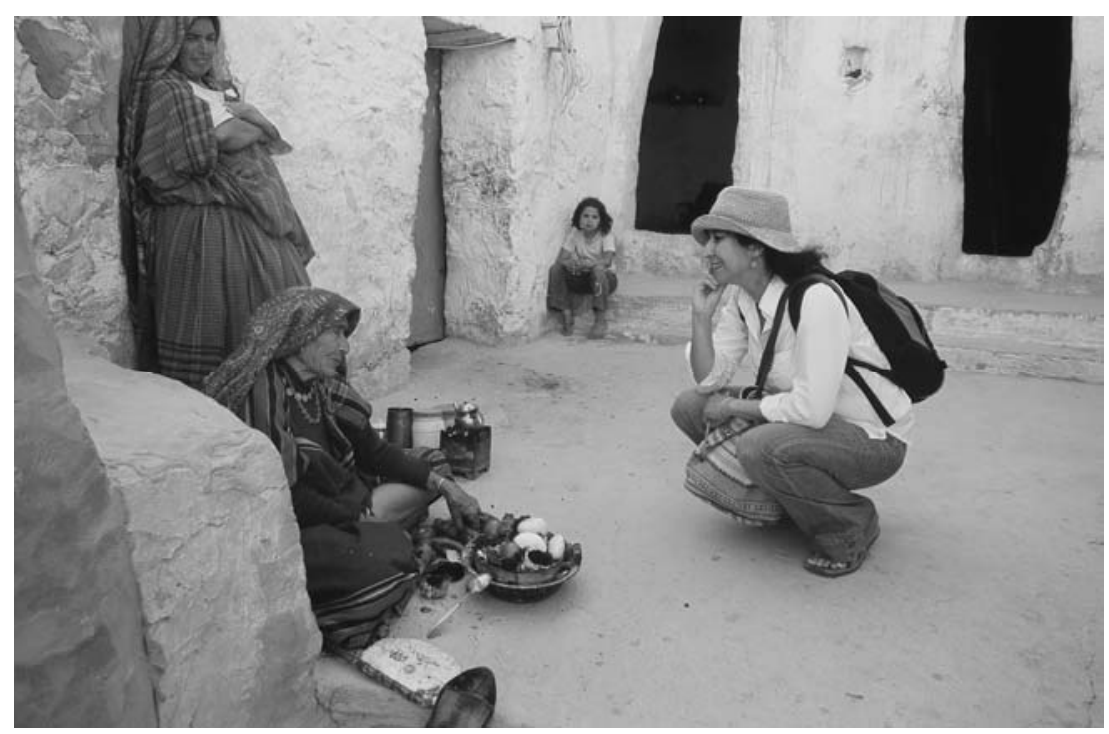

Naima était responsable de la partie linguistique du programme OHLL, puis OMLL : "Le berbère et les Berbères : Diversité linguistique et génétique". Voici une photo qui résume tout ce que représentait Naima. Elle a été prise à l'occasion de notre dernière mission dans le sud tunisien, à Chenini, en juin 2004. Nous avons rencontré dans le vieux village berbère cette dame âgée, en présence de sa fille et de sa petite fille. Elle en est la seule habitante, n'ayant jamais voulu "descendre" dans le village construit récemment au bas de la montagne, offrant un meilleur confort. On remarquera ses vêtements typiques et ses outils de cuisine traditionnels, et elle était berbérophone... Naima, c'est un regard, un sourire, le respect de ses interlocuteurs, une éthique rigoureuse sur le terrain. Tout est dans cette photo, la posture l'atteste.

\section{Jean-Michel Dugoujon, Centre d'Anthropologie, Toulouse, France}

Le dernier projet de Naima Louali, dans le cadre du programme OMLL du laboratoire DDL, portait sur la langue siwi, langue en danger d'Egypte. Plusieurs fois nous avons parlé, avant qu'elle ne parte sur le terrain, de ce qu'elle aurait besoin d'observer et de demander, et à chaque retour elle me racontait ses expériences. Elle parlait beaucoup de la relation spéciale qu'elle pouvait établir 
avec ces derniers locuteurs d'une langue berbère moribonde qui se sentaient isolés et très peu considérés dans un pays devenu entièrement arabophone. Elle racontait l'accueil spécial qu'elle recevait, à s'intéresser à leur langue, à pouvoir presque les comprendre. On lui avait demandé d'écrire un texte là-dessus. Elle avait des notes pour rédiger le profil sociolinguistique de cette langue siwi d'Egypte, et je voulais qu'elle se raconte elle aussi, dans son rapport à eux — une linguiste berbère chez des berbères. Elle n'a pas pu écrire cet article, mais ceux d'entre nous qui étions ses collègues au laboratoire DDL voulons dédier cet ensemble d'articles à sa mémoire, pour qu'elle puisse être associée à nous dans nos réflexions sur la grande diversité des types de locuteurs de langues en danger et sur nos relations à eux, sur nos méthodes de travail, nos frustrations et nos joies à faire ce genre de recherche de terrain.

Colette Grinevald, DDL, Lyon, France 